\title{
A REPRESENTAÇÃO DOS CAMPOS DE VÁRZEA NA CIDADE: UM ESPAÇO DE MEMÓRIA
}

\author{
The representation of holm fields in the city: \\ a space of memory
}

Edmilson Santos*

\begin{abstract}
RESUMO
O tema do lazer vem exigindo um diálogo cada vez mais permanente e eficaz entre as diferentes áreas que têm no espaço urbano fonte de reflexão e construção conceitual. A várzea, enquanto expressão mais popular do lazer esportivo na cidade, tem sido alvo de análise que coloca sobre o seu desaparecimento na paisagem o peso de sua representação. No entanto, é necessário enquadrarmos esse debate a partir de dois enfoques centrais: a cidade (e sua paisagem) e a representação do espaço urbano. Nesse sentido, este trabalho buscou estabelecer uma descontinuidade no pensamento corrente sobre a representação dos campos de várzea, questionando suas pretensões de universalidade e de expressão maior do esporte na cidade.
\end{abstract}

Palavras-chave: lazer; memória; representação.

\begin{abstract}
Leisure is a subject that is demanding a more and more permanent and efficient dialogue between the different areas, which have their source of reflexion, and conceptual construction in the urban space. The holm, as the most popular expression of leisure sports in the city and has been the object of analysis on its disappearance of the weight of its representation. However, it is necessary to focus this debate on two central aspects: the town (and the representation of the urban space). In this sense, this work tried to establish a discontinuity in the current thinking about the representation of the holm fields, questioning its pretension to universality and major expression of sports in the city.
\end{abstract}

Key words: leisure; memory; representation.

Luterana do Brasil).

* Professor Mestre da ULBRA/CELULBRA (Centro de Estudos do Lazer da Universidade 


\section{Introdução}

Durante muito tempo, a várzea ${ }^{1}$ foi o espaço que ancorou o desenvolvimento do esporte como uma das mais importantes práticas culturais das camadas populares nos centros urbanos. Os jogos que aconteciam nesses espaços tinham um duplo significado para a sociedade. Possuíam um lugar na paisagem ${ }^{2}$ que lhe garantia uma visibilidade estética e, enquanto prática social e cultural, um significado simbólico produtor de identidade e memória. Pensar na várzea era pensar no lazer, nos campos, nas ligas regionais, nos encontros de finais de semana e na prática do futebol.

A imagem produzida por esses verdadeiros encontros festivos de finais de semana ficou tão forte no imaginário social que a ausência do lugar na paisagem da cidade levou parte da população, inclusive ex-jogadores, a pensar que a prática esportiva diminuiu na sociedade. Do ponto de vista da relação simbólica criada a partir desses lugares de memória ${ }^{3}$, o que ficou vivo para as comunidades foi o desaparecimento dos campos de várzea e, conseqüentemente, do esporte.

Se, do ponto de vista do imaginário popular, a conclusão é perfeitamente compreensível, para os estudos na área de Educação Física que tematizam a várzea essa proposição necessita ser melhor analisada. Preliminarmente, é possível pensar num outro contexto, onde podemos constatar um crescimento no número de espaços públicos para a prática esportiva; um maior número de esportes estão a satisfazer uma multiplicidade de interesses e a construção de espaços esportivos acessíveis em qualquer clima e horários constituem um verdadeiro paradoxo.

Os campos de várzea eram territórios do público masculino, só existiam jogos nos finais de semana, não havia iluminação artificial capaz de estender o horário dos jogos, eles eram direcionados basicamente para o público adulto

1 Várzea é a denominação utilizada pelos cidadãos da cidade de Porto Alegre para designar aqueles vazios urbanos planos cuja função estava associada à prática do futebol. Os campeonatos comunitários de futebol ocorriam nesses espaços. Várzea, quando se discute no âmbito do futebol, também significa algo amador: futebol varzeano é sinônimo de futebol amador.

2 Alertados por Gröning (2004), não nos atrevemos a delimitar um conceito preciso sobre a paisagem. Essa tarefa, já realizada por geógrafos, arquitetos, pintores, fisiocratas e agricultores, não foi capaz de elaborar um conceito universal. No contexto deste trabalho, nos aproximamos da noção de paisagem que incorpora o componente humano na interpretação dos aspectos visuais da natureza (MAXIMIANO, 2004).

3 Nora (1993) acrescenta a dimensão material e simbólica do aspecto funcional dos espaços. 
e para a prática do futebol. Hoje, há espaços esportivos direcionados para o público feminino. As atividades podem ser realizadas em qualquer hora do dia, existe uma variedade muito maior de modalidades esportivas que estão a atender uma maior diversidade de interesses das crianças, dos jovens e da terceira idade, e há, no caso de Porto Alegre, um número maior de espaços públicos para realização de atividades esportivas de lazer.

Essas breves considerações nos apontam para uma realidade distinta daquela anunciada pelo senso comum: na verdade, a sociedade está ficando cada vez mais esportiva. Por outro lado, não podemos desconsiderar o papel da paisagem na construção do imaginário popular, pois a cidade fornece símbolos à memória coletiva, visuais ou discursivos, e representações sobre o cotidiano que edificam a construção do sujeito.

Nesse caso, o leitor cotidiano da paisagem da cidade elabora sua análise através de uma pauta trazida de um contexto histórico e social diferente e até contraditório (CRICHYNO, 1996). Para melhor compreender essa dinâmica, este ensaio foi concebido.

\section{Lazer, várzea e representação}

Para fazermos uma análise do lazer na cidade, é importante que possamos incluir em nossa pauta de trabalho a várzea. Como já foi dito anteriormente, ela se tornou ao longo dos anos a mais importante expressão do lazer urbano. Compreender o significado da várzea na paisagem da cidade exige pensarmos como a cidade tem sido representada e pensada. ${ }^{4}$

Na busca de tentar compreender esse emaranhado de significações que é a cidade, arquitetos, urbanistas, geógrafos, historiadores e sociólogos têm procurado tecer considerações e teorias que procuram constituir a sua realidade, a sua identidade. Esses movimentos, longe de serem uma atividade desinteressada e neutra, fazem parte de todo processo que transformou a cidade num objeto de disputa e de relações de poder. ${ }^{5}$

4 Essa representação tem como ponto de partida a paisagem, foco principal deste trabalho. $\mathrm{O}$ conceito de paisagem, que alicerça o trabalho, é de Del Rio: "cenário que nos rodeia, participa e conforma nosso cotidiano" (p. 94).

5 Uma leitura interessante nesse sentido pode ser encontrada na obra de Souza e Pesavento (1997), que colocam lado a lado historiadores, jornalistas, poetas e urbanistas na leitura da cidade. 
À medida que trabalhamos com certa idéia histórica de cidade, não podemos desconsiderar o papel de suas representações, enquanto produtora da realidade que se procura analisar. Essa dialética, muito bem expressa no entendimento de relações de poder apresentada pelo pensamento foucaultiano, torna a cidade um objeto que se constrói e é construído no mesmo instante em que buscamos conhecê-la. Não há como nos antecedermos à sua existência. Ela só passou a ser pensada à medida que se tornou necessária para um determinado estágio da cultura. Por conseguinte, ela é refém da história e dos projetos sociais e culturais em curso.

Nesse caso, não há como criarmos uma distinção entre o objeto de investigação como algo dado antecipadamente (a-histórico, portanto) e o sujeito da observação, alguém que chega depois de tudo já estar construído. O sujeito que observa traz consigo uma série de considerações preliminares, acumuladas ao longo do tempo, que não estão no objeto que analisa. Portanto, o surgimento da cidade só pode ser concebido no exato momento em que determinados interesses se voltam para ela e lhe confere algum valor simbólico para a compreensão da cultura, da relação homem/natureza. ${ }^{6}$

É nesse quadro de disputa entre diferentes representações sobre a cidade que poderemos identificar os seus significados. A conseqüência imediata desse pensamento é que não podemos descrevê-la sem o olhar interessado do observador, pois não existe um olhar inocente que capture a essência das coisas. Conseqüentemente, não há uma cidade que possa ser discursada a partir de uma posição de neutralidade que transcenda a história e seja capaz de definir uma realidade universal, fechada e segura, independentemente dos interesses de quem a produz. ${ }^{7}$

Por outro lado, há certo desconforto para o cidadão (bastante receoso com as transformações) em perder os laços com aquilo que constitui, muitas vezes, sua própria identidade. ${ }^{8}$ Conforme considerações de Maximiano (2004),

6 Cf. Angelo Serpa (1999).

7 Os próprios bairros impedem o movimento de garantir uma única identidade à cidade. Do ponto de vista operacional, percebemos nossa cidade a partir de fragmentos captados nos percursos realizados no cotidiano (GOYA, 1995). Utilizando a noção de espaço total de Santos (1985) para análise da cidade, é possível perceber sua realidade como um conceito. A realidade da cidade depende do valor relacional que uma fração de ambiente possui a partir de um sistema total conceitualmente concebido.

8 Uma visão interessante sobre o tema nos é dada por Gröning (2004). Na Alemanha nazista, a paisagem ancorava uma relação de harmonia entre os alemães e a natureza. Para tanto, foi expedida uma norma paisagística que deveria ser seguida por todas as regiões incorporadas pelo regime. "Para que o homem germânico-alemão pudesse sentir-se em casa, as normas paisagísticas proibiam a utilização de plantas que não fossem consideradas nativas do ponto de vista germânico.” (p. 13) 
uma das funções da paisagem é garantir conforto espiritual. Hoje não é mais possível pensar na várzea como um espaço privilegiado de manifestação da identidade esportiva no campo do lazer. ${ }^{9}$

Imerso nesse quadro, o cidadão comum tende a assumir posturas mais conservadoras e a exigir uma volta ao passado (nostalgia). Diante do medo causado pelo desaparecimento das referências, surge uma atitude de defesa que recoloca sobre o passado todo um sentimento de pertencimento perdido no presente. Essa postura cria um determinado quadro que coloca sobre os elementos da paisagem a responsabilidade de garantir a representação do espaço urbano como fora no passado. Isso garante certa tranqüilidade para o cidadão que construiu uma história de vida nos campos de várzea e que está ávido por recuperar a segurança emocional perdida.

A representação da paisagem - a sua força - é produzida a partir de um contexto cuja composição com outros elementos (como o interesse de quem observa e os projetos representacionais em disputa) poderá configurar diferentes cenários, diferentes representações, diferentes intencionalidades. Como ressalta Lynch (1997), "na maioria das vezes, nossa percepção da cidade não é abrangente, mas antes parcial, fragmentária, misturada com considerações de outra natureza"(p. 2). Nesse sentido, a reivindicação de retorno a um passado corresponde apenas ao interesse de um grupo que interpreta a ocupação do solo urbano com outras configurações espaciais como o desaparecimento do espaço de lazer esportivo desse grupo. ${ }^{10}$

Esse quadro permite que pensemos a cidade a partir daquilo que ela tem de plural e não de unitário e estável, pois as posições mais duras, que exigem uma interpretação em termos de totalidade, são elas próprias produto das relações de poder. E é também a partir dessas relações de poder que a cidade é modificada, transformada, (re)inventada e conservada.

Numa outra perspectiva, Bresciani (1997) entende que a todo momento estamos diante de uma cidade nova, sem durabilidade. Não ra-

9 Houve uma certa desterritorialização do lazer como um espaço privilegiado do sexo masculino. As políticas de lazer fizeram das praças e dos parques espaços para confluência de outros projetos esportivos até então desconsiderados. A maior democratização do acesso à escola permitiu que um número significativo de meninas passasse a realizar atividades esportivas. Nesse sentido, não só a prática esportiva passou a incorporar as mulheres, mas também outros espaços passaram a compor a paisagem e novos esportes passaram a ser valorizados e estimulados.

10 Esse desaparecimento está associado basicamente a uma modalidade específica de esporte realizado em espaços públicos, o futebol. Essa memória não é universal, está condicionada aos interesses do público masculino que vivencia a experiência do futebol de várzea. Nesse momento, essa experiência representa uma prática social reservadamente masculina (ELIAS; DUNNING, 1992). 
ras vezes, num emaranhado de significações ou da perda das referências, transformamos-nos em personagens estranhos de nosso próprio cotidiano. Em outro trabalho da autora, ao valorizar o poder do olhar, acentua a importância da experiência visual na construção da cidade (1998).

Para Ceniquel (1994), a legibilidade da paisagem da cidade depende da qualidade espacial-visual específica. Esta é dificultada pela mudança constante no cenário da cidade e do sujeito. Seu olhar a todo o momento se amplia, focaliza e seleciona a paisagem para dar conta de suas necessidades mais imediatas. Como bem retrata Bresciani (1998), "as cidades são antes de tudo uma experiência visual"(p. 237). O desaparecimento dos campos de várzea acabou por eliminar uma experiência emocional responsável por demarcar claramente o território esportivo (futebolístico) e masculino.

Para Harvey (1996), a fragmentação da realidade sensível, apresentada pela cidade através de uma seqüência interminável de camadas, o palimpsesto, impede identificar qualquer permanência. A cidade dribla os argumentos que tentam resumir a sua diversidade num discurso unitário ou totalizante. Diferentemente daqueles que representam a memória da várzea, hoje não há mais espaço para transformá-la na única forma de representação do esporte na cidade. ${ }^{11}$

Do ponto de vista histórico, as cidades brasileiras sofreram suas maiores transformações a partir da década de 60 . Com a concentração da atividade produtiva nas regiões metropolitanas, ocorreu um crescimento acentuado da população nessas regiões. Esse crescimento trouxe como conseqüência uma disputa de diferentes interesses, no que se refere aos locais para habitar, transitar, trabalhar e realizar atividades de lazer na construção representativa da cidade. Conseqüentemente não podemos realizar uma assepsia no contexto histórico e social que a produz cotidianamente para encontrarmos a essência de sua realidade. (SAMPAIO, 1996; ZANATTA, 1999)

É na ocultação do processo de produção da realidade que se encontra a força do realismo. Portanto, o que aparece instantaneamente não é a realidade, mas sim a história. Para se colocar como inevitável, é preciso impedir a dispersão das representações.

Diante de toda a dificuldade causada na construção de um modelo discursivo sobre a cidade e sua paisagem que amarre as diferentes intenciona-

11 O esporte na cidade acabou por incorporar uma multiplicidade de interesses esportivos e de espaços para a sua execução, que não se restringem apenas à várzea. 
lidades, Pesavento (1996) aponta, como uma saída estratégica para sua representação, assumirmos uma visão relativa e fragmentária do urbano. Decorre desse pensamento que a experiência visual, proporcionada pela cidade, não permite predicá-la de qualquer funcionalidade a priori. Quem destaca, valoriza e constrói a paisagem da cidade o faz a partir de todo um significado carregado de intencionalidade. Portanto, representar a várzea não é uma atitude livre de interesses. Seus produtores acreditam que seu a priori possui perenidade, que é possível voltarmos a um estágio original desde que recuperemos a várzea como espaço de valorização do esporte na cidade. ${ }^{12}$

Hoje, não sem muita resistência, o mercado quer assumir o papel de entidade superior, como única autoridade capaz de representar o espaço urbano. Esse movimento tem sofrido forte oposição daqueles setores da sociedade que entendem que a entidade abstrata do mercado não pode se sobrepor aos interesses plurais da vida democrática. Isso porque, conforme Sampaio (1996), falta ao mercado compromisso social com a cidade. Nas regras do mercado, a paisagem agrega um valor comercial cujo maior resultado é o surgimento de uma arquitetura de espetáculo desconstituída de qualquer memória (HARVEY, 1996). No entendimento de Souza (1997), esse movimento representa a própria fetichização do espaço urbano. O legado físico e simbólico do lugar se transforma apenas com uma mudança de interesse econômico.

Daí a importância do plano diretor em regrar a ocupação do espaço na cidade através da composição do maior número de interessados em sua construção. Esse movimento regulador, em algumas realidades, tem diminuído o poder do mercado em transformar a cidade num conjunto de paisagens descartáveis.

A desarticulação do cenário, como bem retrata Severo (1998), cria dificuldades para a preservação da memória, quebra as referências e desarma as identidades. O perigo dessa perspectiva é que a perda das referências compartilhadas coletivamente leva ao enfraquecimento das identidades (LE GOFF, 1996). Conforme Zanatta (1999),

Uma das bases de sustentação da identidade é a memória, pois essa lhe fornece o suporte para que os aspectos multiformes da realidade possam ser percebidos pelos sujeitos que compõem uma formação social, com um conjunto de informações, conhecimentos e experiências logicamente articulados. (p. 1434)

12 É importante salientar que esse desejo não está vinculado à valorização do esporte, mas sim do futebol enquanto expressão da masculinidade. 
Nesse jogo infinito de imagens a que somos submetidos todo dia, não se pode identificar no seu devir qualquer essencialismo. Isso não nos tira a responsabilidade de pensarmos que projeto cultural se tem para oferecer às gerações futuras se elas se transformarem em órfãos da memória. A conseqüência mais drástica desse processo é a amnésia coletiva, como se refere Le Goff (1996). Desse raciocínio resulta, talvez, mais pela sensação do que pela razão, um medo dos varzeanos de perderem um dos eixos que liga a prática esportiva à cidade através dos campos de várzea.

Como já foi apresentada no início do trabalho, a várzea se constituiu ao longo da história esportiva brasileira como o principal espaço de valorização, divulgação e democratização do esporte. As mudanças ocorridas no espaço urbano têm apagado os rastros de sua memória social, que a transformava num local privilegiado para se viver a cena pública e todo um conjunto de relações de valorização da cidadania.

As transformações apontadas anteriormente no cenário das cidades não pouparam os espaços de exorcização da vida comunitária, como os campos de várzea. Isso acarretou uma mudança na relação do cidadão com sua cidade, como observa Rolnik (2000):

[...] quando a cidade se transforma em um lugar absolutamente inóspito, sem qualquer possibilidade de prazer, ao invés de um lugar onde as pessoas se sintam inseridas na harmonia de uma comunidade urbana, o lazer estará restrito a espaços e tempos determinados. (p. 180)

Os espaços de lazer, que representavam a própria expressão do viver em sociedade, em seu aspecto gregário e lúdico, estão cada vez mais sitiados (ANDRADE, 1997). Com isso, a cidade e sua paisagem se tornaram algo inseguro, algo que o olhar deve desviar, diante da violência dos espaços de contato público. Por outro lado, a pressa com que nos relacionamos com ela dificulta o destaque e a valorização da paisagem.

Hoje, modernos espaços esportivos são construídos sem nenhuma relação de intimidade ou de destaque com a paisagem da cidade. Essa nova articulação da paisagem quebra as antigas referências e apaga os rastros de uma memória social construída na cena pública. Como bem observa Andrade (1997), os novos espaços esportivos permitem 
Máxima exposição e transparência arquitetônica; máxima privacidade e isolamento arquitetônico, dois pólos antagônicos que tencionam formalmente a cidade moderna, segmentando de modo brusco o público e o privado, a massa do público. (p. 100)

Numa paisagem poluída de representações, insegura e que se transforma numa velocidade nunca antes vista, o cidadão comum acaba sendo absorvido por imagens descartáveis. Para Souza (1997),

Quando o cidadão não consegue perceber, destacar, selecionar, perguntarse ou lançar um olhar inquisitor e interpretativo sobre as imagens visuais da cidade, é porque as representações nelas contidas são fracas e seus significados imperceptíveis. (p. 110)

Não há mais por que perseguir a paisagem com os olhos se os elementos que são expostos não são capazes de sugerir um laço com o passado. A dialética desinteressante e a reivindicação dos varzeanos parecem sinais de uma luta pela preservação da memória cujo resultado todos conhecemos, mas temos dificuldade de aceitar. A várzea já não representa o futebol, o futebol já não representa o esporte na cidade e o esporte na cidade já não representa mais a memória esportiva de seus antigos praticantes.

\section{A várzea enquanto memória}

Na centralidade dessa discussão, encontramos a memória. A memória enquanto um instrumento de preservação de um determinado grupo social. Esta não pode ser abandonada ou ameaçada de perder-se no tempo. Nem todos os grupos possuem estratégias adequadas para salvaguardá-la (POLLAK,1989) nem de reproduzirem as identidades construídas a partir dos lugares.

A várzea é um espaço de vivência de uma memória compartilhada por um determinado grupo social, cujos campos de significado podem ter uma localização espacial e temporal (BARROS, 1989). Portanto, ao analisarmos a paisagem, não estamos fazendo simplesmente uma avaliação de sua qualidade estética. Há razões históricas, sociais, culturais e emocionais 
que interferem nesse jogo de representações e que constroem conhecimento, a cidade e a identidade dos sujeitos. Conseqüentemente, a várzea enquanto paisagem é um importante "veículo de transmissão às gerações futuras de um tipo de consciência social que confere sentido e profundidade à ocupação do território" (PEREIRA LEITE, 1999, p. 292).

Diante desse quadro que se intensifica com as relações de poder que buscam constituir a memória e a história da cidade através de sua paisagem, faz-se necessário, nas mais diferentes temáticas, preservar a memória para que não sucumbam os testemunhos da história. Sem a referência do que fomos, como poderemos saber em que nos transformamos ou compreender o que está acontecendo? Porém, como já foi dito anteriormente, essa tarefa não pode ser equacionada através de uma operação que coloque sobre a paisagem qualquer responsabilidade por sua representação ou elimine aquilo que é próprio da natureza humana, seu devir histórico.

O pensamento nostálgico não pode ser elaborado à margem de todo valor simbólico que carrega a cidade em suas mais diferentes representações. O desaparecimento dos campos de várzea não nos permite fazer conjeturas universalistas, como se eles fossem os únicos protagonistas da representação do lazer esportivo na cidade.

Quando um setor da sociedade reclama o desaparecimento de seus laços com o passado, não podemos entender suas preocupações para além da intencionalidade legítima de seu grupo. Como já apresentamos anteriormente, a paisagem também pode cumprir o papel na garantia da estabilidade emocional do sujeito. Seu desaparecimento significa uma perda. Diante desse impasse, cabe a nós, enquanto profissionais ligados à construção do esporte, reafirmar nosso compromisso com a história e poder marcar essa passagem das mais variadas formas de registro. Não podemos deixar de referenciar que a várzea é um dos pilares na formação da identidade esportiva urbana. Foi através de seus espaços que o esporte se tornou uma das principais práticas sociais de lazer mais valorizadas e cultivadas. 


\section{Referências}

ANDRADE, Carlos Roberto Monteiro. Confinamento a deriva: sobre o eclipse do lugar público na cidade moderna. In: SOUZA, Célia Ferraz de; PESAVENTO, Sandra Jatahy (Org.). Imagens urbanas: os diversos olhares na formação do imaginário urbano. Porto Alegre: Editora da UFRGS, 1997. p. 97-103.

BARROS, Myriam Moraes Lins de. Memória e família. Estudos Históricos, Rio de Janeiro, v. 2, n. 3, p. 29-42, 1989.

BRESCIANI, Maria Stella. História e historiografia das cidades, um percurso. In: FREITAS, Marcos Cezar (Org.). Historiografia brasileira em perspectiva. São Paulo: Contexto, 1998. p. 237-258.

. Cidade, cidadania e imaginário. In: SOUZA, Célia Ferraz de; PESAVENTO, Sandra Jatahy (Org.). Imagens urbanas: os diversos olhares na formação do imaginário urbano. Porto Alegre: Editora da UFRGS, 1997. p. 13-20.

CENIQUEL, Mario. Paisagem urbano, cenário e percepção: a noção de memória como componente metodológico do projeto. Paisagem e Ambiente: Ensaios, São Paulo, n. 16, p. 85-133, dez. 1994.

CRICHYNO, Jorge. Paisagem urbana: território da cidade e signos do imaginário. Paisagem e Ambiente: Ensaios, São Paulo, n. 9, p. 201-215, dez. 1996.

DEL RIO, Vicente. Paisagem, realidade e imaginação: a percepção do cotidiano. Paisagem e Ambiente: Ensaios, São Paulo, n. 7, p. 93-101, jun. 1995.

ELIAS, Norbert; DUNNING, Eric. A busca da excitação. Tradução: Maria Manuela e Silva. Lisboa: Difel, 1992.

GASKELL, Ivan. História das imagens. In: BURKE, Peter (Org.). A escrita da história: novas perspectivas. Tradução: Magda Lopes. São Paulo: Editora Unesp, 1992. p. 237-271. 
GOYA, Paula Ladin. Percepção do espaço urbano: análise da valorização de paisagens urbanas. Paisagem e Ambiente: Ensaios, São Paulo, n. 7, p. 93-101, jun. 1995.

GRÖNING, Gert. A questionabilidade do conceito de paisagem. Revista Ra'ega, Curitiba, n. 8, p. 9-18, 2004.

HALL, Stuart. A identidade cultural na pós-modernidade. Tradução: Tomaz Tadeu da Silva e Guacira Lopes Louro. Rio de Janeiro: DP\&A, 1999.

HARVEY, David. Espaços urbanos na aldeia global: reflexões sobre a condição urbana no capitalismo no final do século XX. Cadernos Arquitetura e Urbanismo, Belo Horizonte, n. 4, p.171-189, 1996.

LE GOFF, Jacques. História e memória. Tradução: Bernardo Leitão. 4 ed. Campinas: Editora da Unicamp, 1996.

LYNCH, Kevin. A imagem da cidade. Tradução: Jefferson Luiz Camargo. São Paulo: Martins Fontes, 1997.

MAXIMIANO, Liz Abad. Considerações sobre o conceito de paisagem. Revista Ra'ega, Curitiba, n. 8, p. 83-91, 2004.

NORA, Pierre. Entre memória e história: a problemática dos lugares. Projeto História, São Paulo, n. 10, p. 7-28, dez. 1993.

PEREIRA LEITE, Maria Angela Faggin. Visibilidade e cultura. Paisagem e Ambiente: Ensaios, São Paulo, n. 12, p. 289-300, dez. 1999.

PESAVENTO, Sandra Jatahy. Muito além do espaço: por uma história cultural do urbano. Estudos Históricos, Rio de Janeiro, v. 8, n. 16, p. 279-290, 1995.

POLLAK, Michael. Memória, esquecimento, silêncio. Estudos Históricos, Rio de Janeiro, v. 2, n. 3, p. 3-15, 1989.

. Memória e identidade. Estudos Históricos, Rio de Janeiro, v. 5, n. 10, p. 200-212, 1992. 
SAMPAIO, Antônio Heliodório Lima. Cidade ideal, imaginação e realidade. Revista de Urbanismo e Arquitetura, Salvador, n. 6, v. 1, p. 54-65, 1996.

SANTOS, Milton. Espaço e método. São Paulo: Nobel, 1985.

SERPA, Angelo. Clonagem da paisagem: como alguns projetos de intervenção transformam as paisagens urbanas em não-lugares. Paisagem $e$ Ambiente: Ensaios, n. 12, p. 301-309, dez. 1999.

SEVERO, Fernanda. Representações e sentimentos humanos frente às transformações do espaço portoalegrense. Histórica: Revista da Associação dos Pós-Graduados em História da PUC/RS, n. 3, p. 117-126, 1998.

SOUZA, Célia Ferraz de. Construindo o espaço da representação: ou o urbanismo de representação. In: SOUZA, Célia Ferraz de; PESAVENTO, Sandra Jatahy (Org.). Imagens urbanas: os diversos olhares na formação do imaginário urbano. Porto Alegre: Editora da UFRGS, 1997. p. 107-122.

ZANATTA, Beatriz Aparecida; CORRÊA, Margarida Maria da S.; RIBEIRO, Paulo Rodrigues. Estudos regionais: paisagem, memória e identidade. Fragmento Cultural, Goiânia, v. 9, n. 6, p. 1429-1439, nov./dez. 1999. 